\title{
Revisitando o Prólogo Joanino
}

\author{
Revisiting John's Prologue
}

\author{
GILVAN Leite de ARAújo ida
}

\section{Resumo}

O Prólogo do Quarto Evangelho é alvo de debate entre os pesquisadores quanto a sua origem, estrutura, vocabulário, significado e relação com o corpo do Evangelho. Nos tempos modernos, o Prólogo é visto como uma composição dos primeiros dezoito versículos do primeiro capítulo. Contudo, a história da transmissão textual do Quarto Evangelho nega tal pressuposto, sugerindo que o Prólogo foi, ao longo da história, visto como uma seção composta por mais ou menos versículos até chegar ao modelo atual. Levando em consideração que originalmente o Prólogo não era concebido como o modelo atual, qual seria o impacto para o estudo da exegese do Quarto Evangelho, principalmente no que diz respeito ao Prólogo? Nesse sentido, torna-se necessário apreciar os atuais esforços em responder tais questões, bem como recuperar o processo de transmissão textual do Prólogo, como contribuição para o debate atual. Buscar-se-á, portanto, os testemunhos antigos sobre sua estrutura e composição e possíveis concepções, para repropor o debate a respeito do Prólogo Joanino.

Palavras-chaves: Prólogo de João. História do Prólogo Joanino. Quarto Evangelho.

\section{Abstract}

The Prologue of the Fourth Gospel is the subject of debate among researchers as to its origin, structure, vocabulary, meaning and relationship with the body of the Gospel. In

\footnotetext{
a Pontifícia Universidade Católica de São Paulo (PUC-SP), São Paulo, SP, Brasil. Doutor em Teologia Bíblica, e-mail: glaraujo@pucsp.br
} 
modern times, the Prologue is seen as a composition of the first eighteen verses of the first chapter. However, the history of the textual transmission of the Fourth Gospel denies such an assumption, suggesting that the Prologue was, throughout history, seen as a section composed of more or less verses until reaching the current model. Considering that the Prologue was not originally conceived as the current model, what would be the impact for the study of the exegesis of the Fourth Gospel, especially regarding the Prologue? In this sense, it is necessary to appreciate the current efforts to answer such questions, as well as to recover the textual transmission process of the Prologue, as a contribution to the current debate. Therefore, the old testimonies about its structure and composition and possible conceptions will be sought, in order to propose the debate regarding the Johannine Prologue.

Keywords: John's Prologue. History of the Prologue of John. Fourth Gospel.

\section{Introdução}

Habitualmente o Prólogo do Quarto Evangelho é concebido como os primeiros dezoito versículos do primeiro capítulo. A sua construção é truncada, em forma de paralelismo, entre as figuras de Jesus Cristo e João Batista, formando duas narrativas independentes e completas. Segundo Ruiz (2017-2018, p. 315), o Prólogo de João é o texto mais importante do NT e não se encontra nenhuma outra narrativa semelhante em nenhuma outra religião, principalmente na sua afirmação "o Verbo se fez carne" (1,14a). Apesar da afirmação possivelmente hiperbólica do autor, não se pode negar a sua originalidade. O mesmo prossegue afirmando que o Prólogo é o texto do NT que mais tem influenciado a cultura do mundo ocidental, não só da atualidade, mas, também, da antiguidade, como Orígenes e Santo Agostinho, os teólogos medievais como João Escoto, Tomás de Aquino e Mestre Eckhart e os filósofos alemães como Fichte, Schelling e Hegel, sem deixar de citar o Fausto de Goethe, que afirma que o Logos Joanino é o que mantém unido o mundo no mais íntimo do seu ser (RUIZ, 2017-2018, p. 316-317).

As atuais análises filológicas, estilísticas, teológicas se deparam com o pressuposto de que o Prólogo seja uma narrativa composta pelos versículos de 
um a dezoito do primeiro capítulo. Contudo, a história da transmissão textual do Quarto Evangelho apresenta outra realidade, ou seja, a concepção de que o Prólogo seja composto por dezoito versículos do primeiro capítulo é um expediente dos tempos atuais. Nesse sentido, a proposta original do autor pode estar em dissenso com a proposta atual. Talvez o resgate histórico da transmissão textual possa iluminar esta questão e abrir caminho para novas compreensões sobre a composição e a teologia da sessão introdutória do Quarto Evangelho.

\section{História da transmissão do Prólogo Joanino}

Williams (2011, p. 375-386) no seu artigo "Not the Prologue of John" apresenta a história da transmissão do Prólogo do Quarto Evangelho. Segundo o autor, a concepção atual do Prólogo, composto pelos dezoito primeiros versículos do capítulo primeiro, não corresponde ao processo de transmissão deste Evangelho (WILLIAMS, 2011, p. 375). O autor repassa os textos antigos conforme segue: a) Primeiras Versões do NT: Diatessaron de Taciano, refletido nos textos Armênios e Siríacos. Em tais textos o Prólogo compreende apenas os primeiros cinco versículos do primeiro capítulo do Quarto Evangelho. Leva-se em conta que no texto de Taciano existe uma pausa após o versículo dezessete e após o dezoito, como nos textos atuais. Williams (2011, p. 375-381) apresenta os seguintes testemunhos do processo de transmissão textual:

a) Os manuscritos $P^{66}$ e $P^{75}$ coincidem ao apresentar interrupção após o versículo cinco, do primeiro capítulo, e ausência de interrupção após o versículo dezoito.

$P^{66}$ ( \pm 200 d.C.): apresenta separação, espaço em branco, após o versículo cinco, ou seja, os versículos de um a cinco se configuram como um único parágrafo. Nova separação reaparece somente depois do versículo vinte e quatro. 
$\mathbf{P}^{75}$ ( \pm 225 d.C.): possui a mesma separação após o versículo cinco, mas sem o espaço em branco. Nova separação, no capítulo, reaparece somente depois do versículo vinte e nove.

b) Códice Vaticanus (B, séc. IV d.C.). O Códice Vaticanus possui parágrafo após o versículo cinco do primeiro capítulo. Nova interrupção reaparece somente após o versículo dezessete, mas não após o versículo dezoito.

c) Códice Sinaítico ( $N$, séc. IV d.C.). Possui parágrafo nos versículos cinco e vinte e cinco, mas não após o dezoito.

d) Códice Alexandrino (A séc. V). O Códice apresenta várias divisões dentro do chamado Prólogo e, entre elas, após o versículo dezoito. Assim, o versículo dezenove inicia com uma letra maiúscula.

e) Códice Bezae ( $D$ séc. V). Possui início de parágrafo nos versículos seis e quinze, mas não existe nenhuma transição entre os versículos dezoito e dezenove.

f) Códice Freer ( $\mathbf{W} \pm$ séc. VI). O Códice apresenta diversas marcações entre unidades, incluindo o início do versículo dezoito, mas não no fim, ou seja, não existe nenhuma marcação entre os versículos dezoito e dezenove.

g) Lecionários. Os Lecionários antigos não apresentam nenhuma marca de separação entre os versículos dezoito e dezenove. No antigo Lecionário do Rito Bizantino os versículos de um a dezessete do primeiro capítulo formam uma perícope. O mesmo fenômeno ocorre no Lecionário de Rito Armênio. Leva-se em conta que este último Lecionário possui origem no rito grego de Jerusalém, do início do século $V$ d.C. Os primeiros Lecionários Siríacos apresentam duas divisões para o Prólogo Joanino, 1,1-34 e 1,1-28, enquanto no ocidente, a Igreja Latina apresenta os versículos de um a quatorze do primeiro capítulo de João como uma unidade, sendo modificado somente a partir da reforma litúrgica do Concílio Vaticano II.

h) Primeiras Versões do Novo Testamento. O Diatessaron de Taciano (final do séc. II d.C.) apresenta os cinco primeiros versículos do Quarto Evangelho como Prólogo. Nova interrupção surgirá, no primeiro capítulo do Evangelho, somente entre os versículos dezessete e dezoito. 
As versões Latinas são os melhores testemunhos para justificar os dezoito primeiros versículos do Quarto Evangelho como uma unidade. Alguns dos antigos manuscritos apresentam o versículo dezenove como um novo parágrafo, mas este parágrafo é apenas mais um entre os diversos parágrafos entre versículos, tendo ainda separação entre os versículos cinco e seis, ou seja, a quebra entre os versículos dezoito e dezenove não é tão marcante quanto entre os versículos cinco e seis. Nessa linha, o Evangelho Lindisfarne (séc. VII) e o São Galo Stiftsbibliothek ms 60 (séc. VIII) apresentam letras grandes iniciando os versículos seis e dezenove.

Na Vetus Syria existe pausa depois do versículo cinco e quatorze, mas não após o versículo dezoito. A versão Armênia apresenta letras maiúsculas iniciando seções, como após o versículo dezessete do primeiro capítulo. Na versão Etíope, a primeira divisão se encontra somente a partir do primeiro versículo do segundo capítulo (WILLIAMS, 2011, p. 378).

i) Primeiros Comentários. Os primeiros comentários sobre o Quarto Evangelho surgem a partir do segundo século, como o Papyrus Egerton 3, Ptolomeu e Heracleon. Orígenes demonstra que a fala de João Batista termina em 1,17. Esta concepção é confirmada no Diatessaron de Taciano e nos subsequentes Lecionários Gregos que colocam a divisão entre os vv. 17 e 18 e não entre os vv. 18 e 19.

A partir do terceiro século, os exegetas demonstram certa tendência em conceber os vv. 1 a 5 como um bloco, como pode ser observado nos fragmentos $\mathrm{P}^{66}$ e $\mathrm{P}^{75}$. Orígenes, por sua vez, descreve os vv. 3-4 como sendo o princípio do Quarto Evangelho, embora diga o mesmo do v. 29. João Crisóstomo transita entre diversas possibilidades (vv. 1-3; vv. 3-4; vv. 1-6), mas aponta vv. 1-5 como $\pi \rho o o i ́ \mu \iota \alpha$. Agostinho, por sua vez, apresenta a divisão em 1,1-5; 6-14; 15-18; 19,33; mas se refere a 1,1-5 como capitulum primum de João. Cirilo de Alexandria concebe o Prólogo como os vv. 1-17 do primeiro capítulo.

i) Bíblias Impressas. Não foi o Novum Instrumentum de Erasmo (1516) e nem a Poliglota Complutencia os primeiros a imprimir o início de João em grego. Os capítulos 1-6 foram impressos em Veneza em 1504 e 1,1-4 em Tübingen em 
1514. Em 1516 Erasmo imprimiu todo o Novo Testamento Grego ao lado do Latim. Embora espaços ocasionais tenham sido deixados entre linhas, isto não se observa até 1,29. A edição de Estephanus, de 1550, foi a primeira a incluir o número de versículos. Cada versículo era um novo parágrafo, iniciando com uma letra capital, enquanto os capítulos continuavam a ser marcados. Nota-se nesta edição que não existe ruptura depois de 1,18 e em nenhuma parte do primeiro capítulo.

Entre as versões inglesas, a Tyndale New Testament (1526) apresenta pausa em 1,6; 1,11; 1,14; 1,15 e 1,19, enquanto a Bíblia de Genebra (1560) e a King James Bible (1611) marcam novos parágrafos depois de 1,6; 1,15 e 1,19. Nota-se que nestas versões existe a transição entre os vv. 18 e 19, mas não como indicativo de fim de narrativa, apenas como transição como nos versículos anteriores.

As pesquisas de Williams (2011, p. 380-381) terminam apontando a edição de Gnesbach do Novo Testamento Grego de 1777, que atribui um espaço entre os vv. 18 e 19, o que se torna prática para as edições posteriores. De fato, tornouse prática em edições subsequentes do Novo Testamento grego marcar 1,1-18 como uma seção, mesmo que outras divisões menores possam ser marcadas também, como se pode evidenciar nas edições de Scholz (1830), Tischendorf $(1841,1869)$ e Wesrcott e Hort (1881). As edições revisadas da King James Bible omitiram as marcas existentes entre 1,5 e 1,6 e colocaram a marca de parágrafo em 1,19, deixando transparecer 1,1-18 como única seção. Desde o século dezenove, a visão de 1,1-18 como única seção tornou-se cada vez mais comum e tem sido amplamente referida como o Prólogo. Um exemplo disso pode ser encontrado na Bíblia de Jerusalém de 1968, que define 1,1-18, como "Prólogo".

Como foi possível observar, na história da transmissão do Quarto Evangelho, descrito nos estudos de Williams, não estava presente a compreensão de que o Prólogo fosse composto pelos primeiros dezoito versículos. Efetivamente, a transição entre os versículos 18 e 19, marcando o final do que será denominado Prólogo, surge somente a partir de 1777, a partir da edição de Gnesbach, que se torna padrão para as edições posteriores, como 
visto acima. Diante desta realidade, pressupor que o autor tenha construído um Prólogo como um hino e a partir de um hino preexistente parece demasiado hipotético. Isto significa que todas as propostas de busca de um fictício hino primitivo que tenha servido de base para o atual Prólogo, bem como as tentativas de compreensão a partir de sistemas quiásticos ou paralelismos, podem esbarrar numa especulação inadequada. Diante dos desafios que a questão do Prólogo Joanino apresenta, De Boer, recentemente, repropôs Jo 1,15 como o Prólogo original no seu artigo "The Original Prologue to the Gospel of John", no qual observa que estes primeiros versículos descrevem, a partir da narrativa da Criação do Livro do Gênesis, aspectos cristológicos e soteriológicos para a correta compreensão do Quarto Evangelho (DE BOER, 2015, p. 448-467).

Por outro lado, querendo encontrar uma base primitiva para o atual Prólogo, os estudiosos tendem a situar a sua origem dentro dos círculos filosóficos alexandrinos do final do primeiro século, quase aproximando-o da figura de Fílon. Contudo, qual é, de fato, a sua origem, a sua teologia e a sua extensão? Segundo Rochais, o Prólogo do Quarto Evangelho surge como um prefácio geral da obra, mas que, curiosamente, não menciona a intenção do autor e nem faz nenhuma alusão ao conteúdo da obra ou divisão do texto (ROCHAIS, 1985a, p. 5). Rochais, após um longo estudo publicado em duas partes, propõe as seguintes hipóteses: 1) Na base de tudo existe um fragmento de um hino judaico-helenístico que descreve, segundo o gênero literário de certos hinos sapienciais, o destino da Palavra de Deus no mundo. Os fragmentos deste hino se encontram nos versículos 1 , 3 a 5 e 11; 2) a comunidade joanina repete este hino e o modifica a fim de expressar através dele a fé do mistério da salvação advinda e realizada por Jesus Cristo. Nesse momento teriam sido acrescentados os vv. 10 e 12ab; 3) Por razões cultuais ou polêmicas teriam sido acrescentados os vv. 14 e 16 no final do hino; 4) Quando o hino foi anexado como introdução ao Evangelho, o redator final teria acrescentado os vv. 2, 6 a 8, 12C a 13, 15 e 17 a 18, por razões cristológicas (ROCHAIS, 1985b, p. 186-187). Contudo, tal hipótese esbarra no processo de transmissão textual do Prólogo. Caso o hino final já fosse formulado em dezoito versículos construídos pelo 
hagiógrafo, como se explicaria que a transmissão do texto, no decorrer da história, não contempla tal composição?

Tobin, se baseando nos estudos de Rochais, parte do pressuposto que 0 Prólogo não pode ser explicado com base somente na Literatura Sapiencial Judaica, primeiro, por causa do elemento central do hino, ou seja, o "Logos", que na literatura sapiencial judaica está relacionado com a sabedoria; segundo, o forte contraste entre luz e trevas e a associação luz e vida, o que não pode ser confirmado pelo livro da Sabedoria e, terceiro, a identificação do Logos com Jesus encarnado é única (TOBIN, 1990, p. 252-253). Em todo caso, Zumstein afirma que caso tenha existido um hino ao Logos antes que o Evangelho fosse redigido este desapareceu para sempre (ZUMSTEIN, 2017, p. 70).

Nas discussões atuais sobre a estrutura encontram-se defensores de uma possível estrutura em paralelismo ou quiasmo. Girard comenta que existe certa divergência entre os estudiosos. De um lado, existe uma maioria que parte de estudos diacrônicos, mas cada um segue com sua própria hipótese históricoredacional quanto à divisão dos estratos. Por outro lado, outros estudiosos defendem a hipótese da unidade de composição do Prólogo: coerência temática e/ou unidade de vocabulário e/ou análise semiótica. Assim, o autor se dedica a um estudo sincrônico do Prólogo (GIRARD, 1983, p. 5).

Na complexidade de compreensão e divisão do Prólogo, Giblin se propõe a um estudo da estrutura, no qual concebe o mesmo como uma unidade composta pelos dezoito versículos, tendo os vv. 6-8, 15 e 13 como acréscimos que desequilibram a harmonia do Prólogo (GIBLIN, 1985, p. 87).

Betancout dedica dois artigos complementares sobre a questão da redação e estrutura do Prólogo Joanino, nos quais procura evidenciar fases de sua composição. Para tal intento o autor se utiliza da análise estilística a fim de evidenciar que através das diferenças de estilos se possam comprovar distintas fases de elaboração do Prólogo (BETANCORT, 1992, p. 11-40; 1993, p. 27-53).

Viviano, retomando a questão sobre a estrutura do Prólogo, repassa as teorias de Boismard e La Potterie, os quais propõem estrutura quiástica ou paralelismo. Na proposta de Boismard, os vv. 1 e 2 correspondem ao v. 18; o v. 3 
ao v. 17 ; vv. 4 e 5 ao v. 16 ; vv. 6-8 ao v. $15 ;$ vv. 9 a 11 ao v. 14 e, finalmente, os vv. 12 e 13 formariam o centro do quiasmo (VIVIANO, 1998, p. 177), conforme segue:

Quadro 1 - Boismard's chiastic structuring of 1953

\begin{tabular}{|c|l|c|}
\hline $1-2$ & Palavra/Deus = Filho no seio do Pai & 18 \\
\hline 3 & Criação através da Palavra = recriação através de Jesus Cristo & 17 \\
\hline $4-5$ & Palavra como fonte de vida = luz como plenitude da graça & 16 \\
\hline $6-8$ & Testemunho de João Batista & 15 \\
\hline $9-11$ & Vinda da Palavra ao mundo = encarnação & 14 \\
\hline & $\begin{array}{c}12-13 \\
\end{array}$ & \\
\hline
\end{tabular}

Fonte: VIVIANO, 1998, p. 177.

Críticos da estrutura quiástica propõem um sistema de paralelismo, no geral, formando três sucessivos movimentos (VIVIANO, 1998, p. 178):

Quadro 2 - Wave theory

\begin{tabular}{|c|c|c|c|}
\hline 1 & A: vv. 1-2 & B: v. 3 & C: vv. 4-5 \\
\hline 2 & $A^{\prime}:$ vv. 6-8 & $\mathrm{B}^{\prime}: \mathrm{vv} \cdot 9-11$ & $C^{\prime}:$ vv. 12-14 \\
\hline 3 & $A^{\prime \prime}: v .15$ & $\mathrm{~B}^{\prime \prime}: \mathrm{vv} .16-17$ & $C^{\prime \prime}: v .18$ \\
\hline
\end{tabular}

Fonte: VIVIANO, 1998, p. 178

Nesta estrutura o centro se encontra no v. 14, que é o ápice do segundo movimento.

\section{Atual proposta do Prólogo de João}

Qualquer leitor atual ao abrir o Evangelho de João se depara com os primeiros dezoito versículos, os quais formam o chamado Prólogo Joanino. A narrativa é entrelaçada entre dois personagens: Jesus Cristo e João Batista (1,15.9-14.16-18 = Jesus; 1,6-8.15 = João). Este mesmo fenômeno ocorre na narrativa da Paixão, no qual o autor relaciona as figuras de Jesus e Pedro. Em todo caso 
isto é curioso. Por que o autor buscou relacionar os dois personagens (Jesus//João)? Leva-se em conta que isto é bem distinto em comparação com os Evangelhos Sinóticos, que miram diretamente sobre a pessoa de Jesus Cristo.

Segundo Voorwinde, durante o século vinte, o estudo sobre o Prólogo Joanino foi dominado por três correntes: a) Autenticidade do Prólogo; b) Relação com o restante do Evangelho; c) Estruturas (VOORWINDE, 2002, p. 15). A corrente que defende o critério de autenticidade se baseia na identificação das camadas redacionais. Assim, Bultmann afirma que o Prólogo é um claro exemplo de como o evangelista tomou material existente, possivelmente proveniente do gnosticismo, e o reelaborou com acréscimos. Schnackenburg acredita que o autor tomou um primitivo hino cristão com raízes teológicas na especulação sapiencial judaico-helenística e o transformou (VOORWINDE, 2002, p. 15-17). Por outro lado, os esforços de Bultmann e Schnackenburg em identificar o material primitivo que teria servido como base para a composição do Prólogo Joanino recaem num empreendimento especulativo (VOORWINDE, 2002, p. 17). Ainda mais, tal tese explicaria as diferenças gramaticais e de vocabulário em relação ao restante do Quarto Evangelho. Porém, a teoria de um hino pré-existente esbarra num outro problema: qual teria sido este hino primitivo, tendo em vista que não existe absolutamente nenhuma correspondência que sirva de aproximação com o Prólogo do Quarto Evangelho? (CHOLIN, 1989b, p. 343). Além disso, o que seria próprio do hino primitivo e qual seria o acréscimo do hagiógrafo? Para Cholin, qualquer que tenha sido o material utilizado pelo autor, o Prólogo se apresenta como uma nova criação, resultando que o atual texto não deve nada à sua possível origem, bem como que o texto atual é a chave metodológica para o estudo do Quarto Evangelho (CHOLIN, 1989b, p. 359).

Rissi parte do pressuposto de que o Prólogo possui uma linguagem poética, é construído a partir de um "paralelismo semítico" e contém dois poemas independentes. Prosseguindo, Rissi apresenta três problemas que se encontram no Prólogo: 1) Por que João Batista aparece duas vezes no Prólogo (vv. 6-9 e 15)?; 2) Por que o tema da entrada do Logos no mundo também 
aparece duas vezes (vv. 11 e 14); Por que a forma dos vv. 1-13 é diferente dos vv. 14-18? (RISSI, 1977, p. 394).

Quanto à relação entre o Prólogo e o restante do Quarto Evangelho, Barret é do parecer que os temas propostos no Prólogo são retomados teologicamente no restante do Evangelho, o que demonstra uma unidade interna (BARRET, 2003, p. 225). Partindo desse pressuposto, autores recentes estão inclinados a considerar o Prólogo como uma unidade (VOORWINDE, 2002, p. 17). Culpepper, na linha de Barret, também acredita que o conteúdo do Prólogo serve de base para a teologia do Evangelho, ou seja, o que é apresentado no Prólogo vem desenvolvido no corpo do Quarto Evangelho (VOORWINDE, 2002, p. 17-18).

Apesar desses pressupostos, algumas dificuldades permanecem. Assim, Voorwinde apresenta algumas delas: a) no restante do evangelho Jesus não é descrito como Logos; b) os temas da pré-existência e encarnação também não são desenvolvidos no restante do Quarto Evangelho; c) Outras expressões como

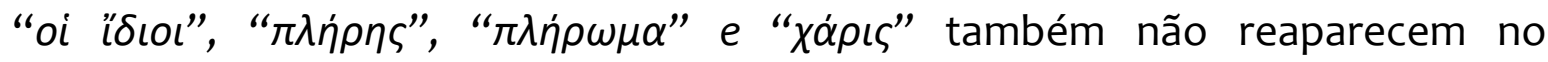
vocabulário do restante do Evangelho. Tais problemas criam problemas para afirmar um conceito de harmonização entre o Prólogo e o corpo do Quarto Evangelho (VOORWINDE, 2002, p. 19).

Segundo Staley (1986, p. 241-242), as análises realizadas na relação entre o Prólogo e o restante do Quarto evangelho não foram realizadas a partir de uma perspectiva lógica. Para este autor, não se pode partir da mesma teológica ou simbólica estrutura para percorrer o Evangelho, apesar de que isto possa ser feito, e nem querer demonstrar que o Prólogo seja um tipo de sumário. Deste modo, Staley afirma: "assim como a primeira estrofe do Prólogo dá o tom da forma simétrica e rítmica de todo o Prólogo, do mesmo modo, a forma simétrica e rítmica do Prólogo define o tom da estrutura da narrativa do que segue" (1986, p. 262). Partindo desse pressuposto, Staley (1986, p. 262) conclui que o Quarto Evangelho apresenta uma simétrica estrutura concêntrica construída, a partir do Prólogo, em cinco seções, cada uma maior que a anterior e cada uma resolvendo algum problema da seção anterior. 
Concebendo o Prólogo de João como uma estrutura de paralelismo em seu interior, pode-se observar o trânsito entre as figuras de Jesus e João Batista, conforme segue:

- $1,1-5$ - Jesus

- 1,6-8 - João Batista

- 1,9-14 - Jesus

- 1,15 - João Batista

- 1,16-18 - Jesus

Leva-se em conta que tal paralelismo não termina com o versículo dezoito do primeiro capítulo, mas o percorre até o final deste. O mesmo fenômeno é encontrado no capítulo dezoito. Porém, o paralelismo deste capítulo se dá entre as figuras de Jesus e Pedro. Tomando em consideração que todo o primeiro capítulo seja construído a partir do paralelismo Jesus-João Batista e o capítulo dezoito a partir do paralelismo Jesus-Pedro, poder-se-ia propor a seguinte divisão:

Quadro 3 - Paralelismos Redacionais

\begin{tabular}{|c|c|}
\hline \multicolumn{1}{|c|}{ Prólogo } & Narrativa da Paixão \\
\hline $1,1-5=$ Jesus $1, \mathbf{6 - 8}=$ João & $18,1-9=$ Jesus \\
\hline $1,10,10-11=$ Pedro \\
\hline $\mathbf{1 , 9 - 1 4}=$ Jesus & $18,12-14=$ Jesus \\
\hline $\mathbf{1 , 1 6 - 1 8}=$ Jesus & $18,15-18=$ João \\
\hline $1,19-36=$ João & $18,19-24=$ Jesus \\
\hline $1,37-51=$ Jesus//discípulos & $18,25-27=$ Pedro \\
\hline
\end{tabular}

Fonte: Autor.

\footnotetext{
${ }^{1}$ Estudo primário que estou desenvolvendo a fim de verificar se, de fato, existe correlação entre as duas unidades. O estudo tem se ampliado para análise de paralelismos como técnica redacional do autor.
} 
Isto evidencia que o Prólogo Joanino não é um elemento estranho que foi anexado ao texto, mas é um expediente utilizado pelo autor para evidenciar a relação Jesus e João Batista (Prólogo) e Pedro (cap. 18). Diante disso, pode-se questionar qual seria a intenção do autor ao aproximar as figuras de João Batista e Pedro a Jesus. Uma primeira resposta seria evidenciar, em relação a João Batista e Jesus, quem possui o direito de messianidade, como ficará evidente posteriormente (cf. Jo 1,19-34//3,23-36). Em relação a Jesus e Pedro, o autor quer evidenciar o papel de cabeça da comunidade (cf. 21,15-19²). Além disso, o autor do Evangelho define quem é João Batista e quem é Pedro, ou seja, "o amigo" (cf. Jo 3,29 e 21,15-17). Claro que a expressão "amigo" possui o sentido pleno no capítulo quinze quando Jesus afirma que o amigo é aquele ao qual foi dado conhecer (cf. 15,15). De imediato, portanto, se pode afirmar quem é João e quem é Pedro no Quarto Evangelho, ou seja, eles são os amigos. Lógico que isto implica rever as traduções do grego para as línguas vernáculas que tendem a tomar um expediente tipicamente joanino e unificar, com significados únicos. Desse modo, os verbos gregos á $ү \alpha \pi \alpha \dot{\alpha} \omega$ e $\varphi \iota \lambda \dot{\varepsilon} \omega$ são traduzidos diretamente

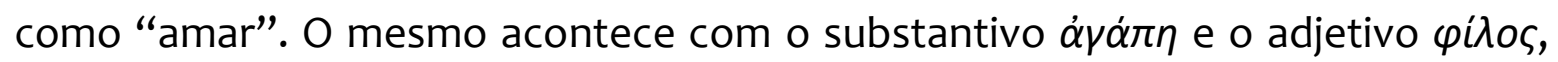
traduzidos como equivalentes, ou seja, "amor". O autor do Quarto Evangelho trabalha com diversas expressões correlatas. Isto exige especial atenção de um tradutor, a fim de manter a distinção, pois se trata de um expediente do autor para construir a sua teologia.

Ainda sobre a estrutura do Prólogo, Cholin classifica os exegetas em dois campos: os partidários de uma estrutura quiástica e os seguidores da estrutura de paralelismo. Para os adeptos de uma estrutura quiástica, não se pode partir de uma leitura linear do Prólogo, mas de uma leitura "bilinear", por meio da qual os autores propõem uma leitura com "vagas sucessivas" e outros a partir de forma de "espiral". O autor em questão proporá uma estrutura que ele chama de "duas dimensões" (CHOLIN, 1989a, p. 194).

\footnotetext{
${ }^{2}$ Equivocadamente, estudiosos veem nesta narrativa um processo de reconciliação entre Jesus e Pedro, após as negações deste último. Contudo, a reconciliação acontece em Jo 21,7.
} 
A proposta quiástica coloca em evidência a proximidade entre os versículos 6-8 e 15, que descrevem a figura de João Batista. Além disso, alguns autores relacionam o v. 1 com o v. 18, os quais formariam um tipo de inclusão. Disso partiria a proposta de uma estrutura de quiasmo, na qual os vv. 6-8 e 15 fazem parte naturalmente (CHOLIN, 1989a, p. 194). Cholin (1989a, p. 194-195) apresenta, então, as propostas de Boismard, seguido por Culpepper, e a proposta de Gese, as quais buscam o elemento central de tais quiasmos.

Os estudiosos que propõem uma leitura linear da narrativa evidenciam que os vv. 6-8 e 15 possuem a função de uma visão cronológica ou progressiva da narrativa, na qual a encarnação do Verbo é o eixo central. Além disso, as numerosas propostas dependem dos temas ou rupturas que cada autor privilegia nas suas respectivas análises, como as propostas de Bultmann ou de Lacan (CHOLIN, 1989a, p. 196). Concebendo o Prólogo como um hino, Boismand propõe que a base teológica seja a narrativa da criação do Livro do Gênesis, enquanto Käsermann busca nos ambientes gnósticos a resposta e Haenchen na Literatura Sapiencial de Israel (CHOLIN, 1989b, p. 344). Tais perspectivas evidenciam a falta de consenso sobre a base de inspiração do autor (CHOLIN, 1989a, p. 189.194).

Cholin, questionando a existência de um hino primitivo que tenha servido de base para a construção do Prólogo, afirma que, caso tenha existido um hino, este seria primitivo e possuiria estilo e construção própria (CHOLIN, 1989b, p. 345). Além do mais, a expressão "Logos" revela características distintivas do hino e do seu autor. Segundo Zumstein (2017, p. 68-69), diversos indícios parecem favorecer a hipótese de um hino pré-joanino: 1) o estilo não é uniforme, visto que a forma poética do Prólogo é interrompida pela prosa (vv. 6-8.13.15); 2 ) o concatenamento das ideias não é harmônico, mas caracterizado por "saltos" (passagem do v. 5 para o v. 6 ou do v. 14 para o v. 15); 3) a linguagem também não é homogênea; 4) há a presença de comentários explicativos (vv. 12c e 13; 14d). Prossegue Zumstein indagando: caso o evangelista tenha reelaborado a partir de uma fonte, é possível distinguir entre tradição e redação? Responde: 1) as duas passagens sobre João Batista (vv. 6-8 e 15) parecem ajuntas redacionais; 
2) muitos estudiosos concebem os vv. 12c e 13 como comentários redacionais; 3) os vv. 17-18 são concebidos como ajuntas redacionais. Os três pontos se fundamentam, para o autor, no seguinte: a) o estilo confessional dos vv. 14 e 16 é deixado de lado em favor de uma reflexão teológica; b) a menção de uma figura humana, Moisés, é única no conjunto do hino; c) pela primeira vez é invocado o nome de Jesus (v. 17), identificado como o Logos; d) a retomada do sujeito da frase com "este" (v. 18) é tipicamente joanina; e) a declaração: "ninguém jamais viu a Deus" (v. 18a) é típica de João (cf. 5,37; 6,46); e f) o conteúdo do v. 18 antecipa uma tese central da cristologia joanina.

Da análise se observa que os recentes estudos partem do pressuposto de que o Prólogo seja composto pelos primeiros dezoito versículos. A história da transmissão textual desmente tal perspectiva. Portanto, querer aplicar métodos de paralelismo, quiasmos, individuar se é um hino, um poema ou qualquer outra coisa se choca com a própria história da narrativa.

\section{Conclusão}

A pesquisa evidenciou que a proposta de compreensão do Prólogo formado pelos dezoito primeiros versículos do primeiro capítulo é recente e não pertence à história da transmissão Quarto Evangelho. Além disso, torna-se perceptível, no conjunto do Evangelho, que relacionar personagens é um expediente utilizado pelo hagiógrafo. Lógico que a questão do vocabulário utilizado gera dúvidas quanto à pertença do atual Prólogo ao conjunto do Evangelho originariamente. Contudo, tendo em vista que relacionar personagens é um expediente utilizado pelo autor como se pode evidenciar nos capítulos um e dezoito, torna-se difícil qualquer tentativa de pensar o Prólogo como uma glosa. Por outro lado, existe uma divergência no que diz respeito ao estilo adotado pelo autor para os dezoito primeiros versículos e o restante do primeiro capítulo, ou seja, enquanto na primeira parte $(1,1-18)$ o autor adota um modelo hínico, no restante $(1,19-51)$ ele adota o modelo discursivo. Isto poderia 
justificar a atual proposta do Prólogo Joanino, mesmo que o processo de paralelismo (Jesus/João) percorra todo o primeiro capítulo.

Em todo caso, durante o desenvolvimento da pesquisa apresentei o início de uma proposta de pesquisa, na qual relaciono o primeiro com o décimo oitavo capítulo, demonstrando que no Quarto Evangelho o autor relaciona a figura de Jesus com as de João Batista e Pedro. Para tal intento o autor do Quarto Evangelho usa um expediente, que é o de intercalar narrativas paralelas e independentes. Creio que uma clara compreensão da proposta do primeiro capítulo, e, no caso, o atual Prólogo, deva levar em conta este expediente para se compreender a real intenção do autor. Além disso, sendo a estrutura dos capítulos um e dezoito um expediente do autor, a teologia do Prólogo Joanino muda substancialmente. Em recente artigo publicado, relaciono as figuras de João Batista e Jesus (ARAUJO, 2018, p. 547-565). Nessa pesquisa evidenciei que a intenção do autor é de descrever as características de cada um dos personagens comparando-as. Portanto, o Prólogo deveria ser analisado não focando unilateralmente na pessoa de Jesus, mas nas duas pessoas que a compõem, ou seja, Jesus e João. Como o início da narrativa da paixão, o foco recai sobre as figuras de Jesus e Pedro. Leva-se em conta que a relação Jesus-João Batista e Jesus-Pedro abrange todo o capítulo primeiro, no primeiro caso, e todo o capítulo dezoito, segundo caso. Tal expediente é, também, aplicado a outros personagens no restante do Quarto Evangelho.

O autor, ao aproximar as figuras de João e Pedro à de Jesus, talvez tenha a intenção de sublinhar a importância desses na missão de Jesus, pois os dois são configurados como "amigos", que é um dos elementos centrais no discipulado joanino (cf. Jo 15).

Esta pesquisa não levou em consideração outros aspectos como a cristologia, principalmente o debate a respeito do "logos" joanino. O tema é relevante e complexo. Na realidade, o objetivo desta pesquisa foi evidenciar a problemática da transmissão textual do Prólogo Joanino e sua importância para os estudos dos seus aspectos teológicos. 


\section{Bibliografia}

ARAUJO, G. L. João, A Testemunha, no Quarto Evangelho. Revista Atualidade Teológica, v. 60, p. 547-565, 2018.

BARRET, C. K. El Evangelio Según San Juan. Madrid: Ediciones Cristiandad, 2003.

BETANCORT, J. B. Notas sobre la Historia de la redacción y estructura del texto de Jn 1,1-18. (I) Fortunatae, p. 11-40, 1992.

BETANCORT, J. B. Notas sobre la Historia de la redacción y estructura del texto de Jn 1,1-18. (II). Fortunatae, p. 27-53, 1993.

CHOLIN, M. Le Prologue de L'Évangile Selon Jean. Structure et Formation. Partie I. Science et Esprit, v. 41, n. 2, p. 189-205, 1989 a.

CHOLIN, M. Le Prologue de L'Évangile Selon Jean. Structure et Formation. Partie II. Science et Esprit, v. 41, n. 3, p. 343-362, 1989 b.

DE BOER, M. The Original Prologue to the Gospel of John. New Testament Studies, v. 61, p. 448-467, 2015.

GIBLIN, C. H. Two Complementary Literary Structure in John 1:1-18. Journal of Biblical Literature, v. 104, p. 87, 1985.

GIRARD, M. Analyse Structurelle de Jn 1,1-18: L'unité des deux Testaments dans la structure bipolare du Prologue de Jean. Science et Sprit, v. 35, p. 5-31, 1983.

RISSI, M. John 1:1-18 (The Eternal Word). Interpretation, v. 31, n. 4, p. 394-401, 1977.

ROCHAIS, G. La Formation du Prologue (Jn 1,1-18). Partie I. Science et Esprit, v. 37, n. 1, p. 5-44, $1985 a$.

ROCHAIS, G. La Formation du Prologue (Jn 1,1-18). Partie II. Science et Esprit, v. 37, n. 2, p. 161-187, 1985 b.

RUIZ, M. R. La Cristología del Prólogo de San Juan. En la investigación Juanica más reciente. Fortvnatae, 28, p. 315, 2017-2018.

STALEY, J. The Structure of John's Prologue. The Catholic Biblical Quarterly, v. 48, p. 241$242,1986$.

TOBIN, T. H. The Prologue of John and Hellenistic Jewish Speculation. The Catholic Biblical Quarterly, v. 52, p. 252-253, 1990. 
VIVIANO, B. T. The Structure of the Prologue of John (1:1-18): A Note. Revue Biblique, 1946, v. 105, n. 2, p. 176-184, avr. 1998.

VOORWINDE, S. John's Prologue: 'Beyond some impasses of twentieth-century scholarship'. WTJ 63, p. 15-44, 2002.

ZUMSTEIN, J. Il Vangelo secondo Giovanni. V. 1: 1,1-12,50. Torino: Claudiana, 2017.

WILLIAMS, P. J. "Not the Prologue of John": Journal for the Study of the New Testament, v. 33, 2011. p. 375-386.

RECEBIDO: 01/06/2020

RECEIVED: 06/01/2020

APROVADO: 03/08/2020

APPROVED: 08/03/2020 